\title{
Injuries to unborn children: Extracts from the report of the Law Commission
}

We are printing, by kind permission of the Law Commission, two sections of the report of the Law Commission on injuries to unborn children. This report was the result of a request to the Law Commission by the Lord Chancellor at the time (Lord Hailsham of Saint Marylebone) to advise on 'what the nature and extent of civil liability for antenatal injury should be'. The Law Commission followed its usual practice in such circumstances of consulting various bodies and obtaining expert advice on the subject and then embodying the results in a working paper (Working Paper No. 47 injuries to unborn children) published on 19 fanuary 1973, which preceded their report (Cmnd 5709). Meanwhile a Royal Commission is considering much wider issues of civil liability for injury (including antenatal injury) but the terms of reference for the Law Commission were much narrower and confined to the position of children injured before birth. In the section relating to the present law the report makes it clear that it is probable that liability under the common law already exists.

The Scottish Law Commission has also issued a report (Cmnd 537I). They were given different terms of reference and came to somewhat different conclusions.

We are printing from this long report the paragraphs discussing the medical background and the summary of recommendations. As will be evident on reading the paragraphs on the medical background to injuries to the unborn child, events are moving very rapidly, particularly in the study of congenital defects and the effects of drugs but the problems of proof present great difficulty. Other causes of injury to the unborn child are better known to the general public: for example, those following the illness, infection and disease of the mother during pregnancy, injury caused in attempted termination of pregnancy and the risks resulting from the mother's condition. The summary of the recommendations sets out very clearly the legal position of the unborn child, as the Law Commission sees it, arising from injury before birth, the final conclusion being that 'legislation is desirable'.

These extracts from the report, apart from their intrinsic interest, lead on to the paper by $\mathrm{Mr}$ Kennedy and Dr Edwards in which they set out their criticisms of it, and provide quick references to the original document.

\section{The prevalence of abnormal births}

In 1971 there were 905600 births in the United Kingdom. This number has been estimated to be the result of 74 per cent of all pregnancies, 15 per cent ending in miscarriage and II per cent being medically terminated. 1 The number of live births exhibiting significant abnormalities is very high. The estimates we have received from different medical commentators have varied, probably because different views are held as to what should be termed significant and also the time at which the child was examined. Examinations at birth produce lower figures of incidence. The lowest estimate we have received, startling to a layman, was between I per cent and 2 per cent; other estimates went higher than 5 per cent. We were told by the Medical Defence Union that there were 1000 handicapped children born in the United Kingdom every weeko and that a child suffering from cerebral palsy is borrs every eight hours.

Medical knowledge of the causes of congenital defect - an expanding science

Consultation has left us in little doubt that we are in an era of rapidly expanding knowledge as to the aetiology of congenital defects. It is equally true that the ability to diagnose fetal deformity before birth by, for example, diagnostic radiology or amniocentesis ${ }^{2}$, is also increasing. In general the types of prenatal injury which we mentioned in working paper no. $47^{3}$, trauma, injury during birth, drugs, abortifacients, irradiation and diseases, were accepted as valid. There was, however, a good deal of doubt expressed as to whether direct trauma to the mother could ever cause fetal injury without a spontaneous abortion and the particular examples

${ }^{1}$ The estimates on pregnancies are those of Professor François Lafitte: New Society, 14 December, 1972, p 623.

${ }^{2}$ Amniocentesis, ie, the procedure whereby a sample is taken of the fluid in the uterus in which the fetus is floating, with the object of analysing the fluid and obtaining data on whether the fetus may be born with congenital defects.

${ }^{3}$ Working paper no. 47 paras 6-16. 
which we mentioned ${ }^{4}$ were considered very doubtful cases. However, it was not disputed that, where the mother died before the birth as a result of trauma, the lack of oxygen between her death and the child's subsequent birth (by caesarian section) could cause damage to the child.

\section{The effect of drugs}

There are known to be about 1500 drugs having teratogenic ${ }^{5}$ effects with varying (usually slight) degrees of risk. However, particularly in relation to drugs, the aetiology of deformities is the subject of dispute. This was a common theme running through nearly all the medical comments we received. It seemed to be generally agreed that no drug could ever be guaranteed safe for the fetus and the point was made with some emphasis that a pregnant woman would become virtually untreatable if no small risk to the fetus could ever be ignored. Nevertheless, it seems clear that, in addition to thalidomide, the terrible teratogenic effect of which is no longer in doubt, there are other drugs which present a substantial risk of damage to the fetus if taken by a pregnant woman. Examples, which have been mentioned to us, include stilboestrol, which, when prescribed for pregnant women liable to miscarriages in the hope of preserving a pregnancy, has been followed by the development of vaginal cancer in their adolescent daughters, anticonvulsant drugs, causing cleft palates; antibiotics causing mottled teeth; progestogens causing severe virilization $^{6}$ in the female fetus with permanent effect on the genitalia; and some drugs used in the treatment of diabetes. The chance ${ }^{7}$ of a defective contraceptive pill damaging a fetus was accepted as a possibility meriting most serious consideration by one eminent physician. In the opinion of some doctors pregnant women should not, without prescription, take aspirins, laxatives or even vitamins, but, despite this opinion, 82 per cent of pregnant women in the United Kingdom take prescribed drugs during pregnancy and 65 per cent take self-medicants.

\footnotetext{
4That is, that a child was born crippled as a result of injury sustained by his mother in a railway accident: that a child being born with club feet was caused by his mother's involvement in a tramcar accident: that a child's brain damage and epilepsy were caused seven months before birth when his mother was involved in a road accident wherein she was rendered a paraplegic. See working paper no. 47, para 8.

${ }^{5}$ Teratogenic, ie, capable of causing damage to the fetus.

${ }^{6}$ Progestogens are substances with an action like that of the ovarian hormone progesterone. Cases arise where excessive intake of such hormones by a female can result in the development of male characteristics, ie, virilization.

${ }^{7}$ We referred to this hypothetical case in para 38 of working paper no. 47 .
}

\section{Poisonous waste}

An example of poisonous waste causing prenatal injury was reported in The Times of 21 March 1973 Twenty years ago the coastal waters of Minamat, a town in south-western Japan, were polluted by industrial waste containing methyl mercury which? was absorbed by fish and shellfish. The children of pregnant women who consumed the polluted fish were born with deformed limbs and an impairech nervous system. Adults who accumulated mercury in their systems from eating the fish suffereds permanent paralysis, loss of coherent speech and $b$ malformation of the eyes. After litigation extending over 17 years the chemical company responsibles for the pollution was ordered to pay compensation totalling $£$ I 500000 to the victims of the disaster.

\section{The efiects of illness, infection and disease}

It is clear that there are infections and diseases whicho may have an adverse effect on the fetus. Infections such as syphilis and rubella ${ }^{8}$ can cause considerables damage. Other infections which may have tera $\frac{\mathbb{O}}{0}$ togenic effects were suggested to us by the Medica足 Defence Union; they included smallpox and vaccinito virus, chicken pox and influenza. Even withou黑 infection, there are dangers. Although prematurity will more often than not be caused by, rather than cause, an abnormality; prematurity (and, indesd postmaturity) can result in poor prospects for child in terms of health and development. Pres maturity can also be caused by an incompeten cervix, which ought to be diagnosable. An eclamptio mother ${ }^{8}$ should have the birth induced, although this itself carries a risk to the fetus. Other condie를 tions in the mother, such as toxaemia, 10 hydramn? ios ${ }^{11}$, diabetes mellitus ${ }^{12}$ and thyroid disorders a carry risks for the fetus. Immunization against: Rhesus disease ${ }^{13}$ of a mother can cause haemolysis ${ }^{15}$ in the fetus; this can be treated by intrauterin 8 blood transfusion, a process carrying, however, it own risks.

${ }^{8}$ Rubella, ie, German measles.

${ }^{9}$ Eclamptic mother, ie, a mother suffering from pro eclampsia, which if untreated can lead to eclampsia, condition manifested by fits and coma and even death. N ${ }^{10}$ Toxaemia, ie, a condition denoting a hostile substançe in the blood.

${ }^{11}$ Hydramnios, ie, an excess of fluid in the uterus whicts can be associated with a cogenitally abnormal fetus. ${ }^{12}$ Diabetes mellitus is the common form of diabet 8 attributable to a failure of the pancreas as contrasted with diabetes insipidus attributable to a defect in the pituitary gland.

${ }^{13}$ For details of Rhesus disease see footnote ${ }^{20}$ below.

${ }^{14}$ Haemolysis, ie, a condition denoted by the destruction of the red blood corpuscles, which can be fatal unles treated. 
Injury caused in attempted termination of pregnancy

It is apparent that there is an area of potential risk to a fetus surviving an unsuccessful attempt to terminate a pregnancy. The case is known, for example, where there was a failure to diagnose twins and at operation for termination of the pregnancy only one fetus of the undiagnosed pair had been evacuated from the uterus ${ }^{15}$. In New York, where over 400000 abortion operations have been performed after the 24th week, 73 live births have taken place despite the abortion operations. In two of these cases the infant has survived, one in a seriously handicapped state ${ }^{16}$.

\section{Risks in prenatal treatment and childbirth}

There is a slight risk to the fetus even in some properly and carefully performed diagnostic investigations such as amniocentesis ${ }^{17}$ and some forms of treatment such as intrauterine transfusion. General anaesthetics and treatments for toxaemia also carry a slight risk to the fetus. It was the general opinion of the doctors whom we consulted that treatment of the mother during childbirth could also cause injury to the infant.

\section{Risks resulting from the mother's condition}

Certain conditions of the mother make it statistically more probable that a child will suffer an infirmity or be abnormal. Women over 40 have an increased chance of bearing a mongol child or a child born with a defect of the central nervous system. A diabetic mother is said to have twice the normal chance of having a disabled child. Where a woman has borne one child suffering from cystic fibrosis 18 the risk for the next child being similarly affected is one in four. An extreme case mentioned to us was that of a mother who was a dwarf due to osteogenesis imperfecta19, a condition in which there is a 50 per cent chance of it being passed on to the child.

\footnotetext{
${ }^{15}$ We have been so informed by the Royal College of Physicians.

${ }^{16} \mathrm{We}$ have been so informed by the Medical Defence Union.

${ }^{17}$ See footnote ${ }^{2}$ above.

${ }^{18}$ Cystic fibrosis, ie, a familial disease denoting a disorder of the mucus-secreting glands in the body and characterized by excessive respiratory infections and failure to thrive and early death.

${ }^{19}$ Osteogenesis imperfecta, ie, a rare condition in which the bones are brittle and fracture on relatively trivial strains.
}

The effect of events occurring to a parent before conception

It was accepted that events happening to a parent could be the cause of abnormalities to a child subsequently conceived. Radiation may affect the reproductive germ cells of either parent. As another example, it is possible that failure to give a Rhesus-negative woman anti-D gamma globulin in the first 72 hours after the birth of her first child, if it was Rhesus-positive, would lead, in subsequent pregnancies, to her later child suffering avoidable Rhesus disease ${ }^{20}$.

\section{Difficulties of proof}

Again and again in our consultation with the medical profession it was emphasized that the whole field of teratology is in a state of development and that, in many cases, the evidence as to the cause or causes of a child's congenital disability will be inconclusive. There is no doubt that proof of the causation of prenatal injury presents great difficulty at present and will continue to do so in many cases in the foreseeable future. We are, however, left with the clear impression that rapid progress is being made and that we must be prepared for far greater certainty both in the identification of teratogenic agents and the proof of causation of specific disabilities in the future.

\section{Medical advice during pregnancy}

The development of medical and social services has led to more and more women seeking medical advice during pregnancy. This, together with the increase in medical and scientific knowledge referred to in previous paragraphs, is bound to lead to greater risks of medical advisers failing to tender the correct advice or to prescribe and give the correct treatment. Section $I(I)(b)$ of the Abortion Act $1967^{21}$ provides that a medical practitioner is not guilty of an offence under the law relating to abortion when he terminates a pregnancy if two

${ }^{20}$ The Rhesus factor (so-called because it appears in the blood of the Rhesus monkey) is a constituent factor in the blood of $84 \%$ of human beings, who are called Rhesus-positive. A person lacking this factor is called Rhesus-negative. A Rhesus-negative mother may develop antibodies against the Rhesus factor from a transfusion of Rhesus-positive blood or by bearing a child which is itself Rhesus-positive. The Rhesus-negative mother's antibodies may, in a subsequent pregnancy, pass into the fetal circulation and thus cause haemolysis of the fetal blood of the later fetus. The mother may be immunized by treatment with anti-D gamma globulin after her first confinement.

${ }^{21} 1967$ c 87. 
medical practitioners are of the opinion, formed in good faith, that 'there is a substantial risk that if the child were born it would suffer from such physical or mental abnormalities as to be seriously handicapped'. Whilst the Act has no direct bearing on questions of civil liability we think it probable that a doctor would be held to be failing in his duty of care to a pregnant woman if he failed to warn her that it could be reasonably foreseen that there was a risk of her bearing a disabled child and that this was such as to make an abortion legal. Whether a child, thereafter born disabled, ought to be able to recover damages from the doctor is a matter which we consider and answer in the negative later in this report.

In addition to the possible liability upon doctors and others advising pregnant women, referred to in the last paragraph, every new positive identification of a teratogenic agent or procedure creates a new sphere of duty, for example, to refrain from prescribing a drug or treatment. Moreover, lack of care in performing therapeutic or diagnostic treatment may lead to a child being born with disabilities caused thereby. We are very conscious of these added responsibilities which are being placed upon the medical profession and which have been emphatically brought to our notice by the profession. If our view of the way in which the courts would decide cases where prenatal injury is caused by negligent conduct is correct the proposals we make in this report will in no way add to the potential liability of those who advise and treat women during pregnancy, but we have, in framing these proposals, kept in mind their difficulties. Particularly in relation to the possibility of allowing an action in those cases where the allegation is that a child has suffered harm from the fact of being born, those difficulties have been a major factor influencing us in the conclusion at which we have arrived. We are also well aware that parents of disabled children sometimes suffer (naturally but illogically) from feelings of personal guilt which it is a natural instinct to transfer elsewhere. It would be a sorry result of the legislation we propose if it were to lead to the harassment of the medical profession with unfounded claims. We have taken care that the draft Bill which we append to this report will not, if it is eventually embodied in legislation, have any such effect.

\section{Summary of recommendations}

The following is a summary of the recommendations in this report:

I) Legislation should deal with the rights of a living person and no rights should be given to the fetus.

2) The general principle should be that wherever prenatal injury is caused intentionally, negligently or by a breach of statutory duty there should be liability for that injury.

3) As a general rule, whenever there is liability in tort at common law to a parent for an act of omission which causes prenatal injury, the chil霓 should be entitled to recover damages.

4) Liability to the child ought not to be exclude $\overline{\bar{\phi}}$ merely because the mother has herself suffered no actionable injury.

5) As a general rule, whenever a breach of statutory duty owed to a parent causes prenatas injury to the child, he should be entitled to recoves damages for his disability. In the same way as we. recommend for actions in tort at common law? liability to the child should depend upon liability in tort to the parent.

6) As a general rule, legislation should no permit a right of action by a child against its ow mother for prenatal injury.

7) As an exception to the general rule, where mother causes prenatal injury to her child by her negligent driving of a motor vehicle, she should bo liable to her child.

8) If a mother is liable to her child for heep negligent driving, any person jointly liable with he should have a right to claim contribution from hers

9) A mother's negligence should be available as partial defence to a tortfeasor where her fault has. contributed to her child's prenatal injury.

Io) In an action by a child for prenatal injug ज्ञ defendant should be entitled to rely upon a contrigc tual term binding on the mother excluding limiting his liability either towards her or towards her unborn child.

II) In an action by a child for prenatal injury $\$$ defendant should be able to rely upon a mother' voluntary assumption of risk.

12) The rule that a tortfeasor 'takes his victing as he finds her' should apply where a pregnant woman is injured by the defendant's fault; the fact that she is bearing a child should be treated as one of her 'characteristics and constitution'.

13) Preconception injury to a parent causin prenatal injury to a child shall found a cause of action in the child only if the parents or either of them neither knew nor ought to have known at the time of conception of the risk of a child being bori disabled as a result of the relevant injury.

14) Where a father is sued for prenatal injunz caused prior to or at conception, the limitation on liability for preconception injury resulting from the parent's knowledge should not apply.

I5) There should be no claim for prenatal injury otherwise than at the suit of the first generation.

16) No legislation resulting from our recomf mendations should interfere with the scheme of the Nuclear Installations Act 1965 but, in the light of our report and any legislation implementing ie consideration should be given to its amendment. \&

17) There should be no liability for 'wrongf life'.

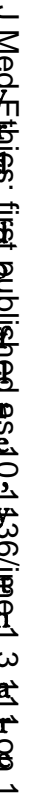


18) Where a disability is caused at conception by a wrongful act, then there should be liability.

19) A father should not be exempt from liability to his child.

20) There should be a special provision codifying, in the context of prenatal injury, the common law rule that a person acting in a professional capacity is not liable for negligence if he acts in accordance with the then received professional opinion.

2I) Damages should be assessed as if the prenatal injury had been inflicted after a birth without the disabilities due to the prenatal wrong.

22) There should be no claim for damages for loss of expectation of life unless the plaintiff survives birth by 48 hours.

23) For the purpose of the limitation of actions, claims for prenatal injury should be treated in the same way as claims for personal injury. The 'custody of a parent' rule should not apply to claims for prenatal injury.

24) Legislation implementing our report should apply to all causes of action accruing after the passing of the Act.

25) For the reasons stated we consider that legislation is desirable.

(Signed) SAMUEL CoOKE, Chairman Claud Bicknell

Aubrey L. Diamond

DEREK HODGSON

J M CARTwRIght Sharp, Secretary

NORMAN S. MARSH 